\title{
Novel Products of the Acidogenic Fermentation of Methanol during Growth of Eubacterium limosum in the Presence of High Concentrations of Organic Acids
}

\author{
By N. D. LINDLEY, * P. LOUBIÈRE, S. PACAUD, C. MARIOTTO AND \\ G. GOMA \\ Département de Génie Biochimique et Alimentaire, INSA, Avenue de Rangueil, \\ 31077 Toulouse Cédex, France
}

(Received 19 May 1987; revised 28 July 1987)

Methylotrophic growth of Eubacterium limosum, a fermentative anaerobe, necessitates the production of butyric acid in quantities proportionate to the methanol dissimilatory flux in order to balance the reducing equivalent status of the cell. Supplementing the medium with low concentrations $(<100 \mathrm{mM})$ of butyrate decreased the quantity of methanol dissimilated and brought about a corresponding shift in organic acid production in favour of acetic acid. At higher supplement concentrations the growth rate decreased and synthesis of caproic acid and an unidentified compound, most likely a biopolymer, occurred. In fed-batch cultures similar levels of butyrate were necessary to bring about these biotransformations. The addition of a $\mathrm{C}_{2}-$ unit to supplemented organic acids was not restricted to those acids normally involved in the acidogenic metabolism of $E$. limosum, a finding, which may be of potential biotechnological importance.

\section{INTRODUCTION}

Acidogenic methylotrophs, first isolated by Zeikus et al. (1980) and Genthner et al. (1981), have been studied in a number of laboratories, of ten with a view to exploiting their potential as organic acid producers. Much of the published work has been directed towards optimizing the fermentation medium, or to establishing the biochemical sequences leading to the formation of acetyl-CoA (the first multicarbon intermediate): a condensation reaction between equimolar quantities of methyl corrinoid and an intermediate thought to be carbon monoxide (Kerby et al., 1983). Although many aspects of the biochemistry of methylotrophic acidogenesis remain obscure, the accumulated data do enable some conclusions to be drawn concerning the regulatory principles controlling the extent of both growth and organic acid production. The overriding factor governing the fermentation of methanol is related to the reduced nature of the substrate necessitating a cosubstrate, $\mathrm{CO}_{2}$, and the production of a fermentation end-product of a more reduced level than the substrates in order to balance the reducing equivalent status of the bacterium. The production of butyric acid is therefore intimately coupled to the dissimilation of methanol and enables a commercial process to be envisaged. Variations in the methanol dissimilatory flux bring about a corresponding change in the ratio of acetic and butyric acids produced, endowing Eubacterium limosum and similar non-homoacetogenic methylotrophs with a degree of physiological flexibility. The theoretical limits to the methanol-fermenting metabolism of $E$. limosum have recently been summarized by two stoichiometries representing homoacetic and homobutyric fermentations (Pacaud et al., 1986a):

$$
\begin{aligned}
& 10 \mathrm{MeOH}+2.94 \mathrm{CO}_{2} \rightarrow 2.87 \text { Butyrate }+1.48 \text { Cell C } \\
& 10 \mathrm{MeOH}+7.86 \mathrm{CO}_{2} \rightarrow 8.19 \text { Acetate }+1.48 \text { Cell C }
\end{aligned}
$$

By creating a feed-back inhibition within the acetate-producing sequence and ultimately reversing the direction of this sequence by supplementing the medium with various 
concentrations of acetate, Pacaud et al. (1986a) were able to achieve homobutyric fermentations of methanol by E. limosum, improving the biotechnological potential of the organism. However, in a separate study the same authors (Pacaud et al., 1986b) demonstrated that a range of saturated organic acids inhibited growth when the medium concentration surpassed a threshold value, dependent upon the molecular mass of the acid. This observation, particularly as regards butyric acid, may well fix an upper limit for production. In this study the effect on global fermentation parameters of supplementation with butyrate (and other short-chain organic acids not normally associated with methylotrophic acidogenesis) was investigated since any shift in the pattern of acid production at high product levels is likely to have important biotechnological implications. The results obtained allowed certain physiological conclusions to be drawn, and they highlight potential limitations to the biotechnological application of methylotrophic acidogenesis. Confirmation of the induction of novel biotransformation reactions at high organic acid concentrations is discussed with reference to fed-batch fermentation techniques, and alternative strategies are proposed.

\section{METHODS}

Organism. Eubacterium limosum B2 was obtained from Dr E. Samain (INRA Lille, France); this strain was first isolated from pea-blanching wastes.

Media and cultivation. The organism was grown under strictly anaerobic conditions in the medium described previously (Pacaud et al., 1985) at initial $\mathrm{pH} 7.4$ and $37^{\circ} \mathrm{C}$ in sealed tubes. Methanol $(100 \mathrm{mM}$ ) and carbon dioxide $\left(60 \mathrm{~mm}\right.$, i.e. $5 \mathrm{~g} \mathrm{KHCO}_{3} \mathrm{1}^{-1}$ under $15 \% \mathrm{CO}_{2}$ ) were the carbon sources. Organic acids were added to the medium at various concentrations as salts. The redox potential of the sterilized medium was adjusted $18 \mathrm{~h}$ before inoculation by the aseptic addition of cysteine. $\mathrm{HCl}$ and $\mathrm{Na}_{2} \mathrm{~S}$ solutions. Inoculation was with $5 \%$ volume of exponentially growing cell suspensions. The same medium was used for fed-batch cultures prepared in a 2 litre glass fermenter (initial medium volume, 1 litre) with automatic control of $\mathrm{pH}$ to 7.4 ; it was supplemented periodically with essential salts and carbon substrates as required.

Analytical methods. Growth rates were calculated from optical density measurements at $660 \mathrm{~nm}$ against a freshly prepared medium blank. Biomass values were estimated during growth by optical densities, and at stationary growth phase by a direct gravimetric membrane filtration method.

Substrate and product concentrations were measured by gas chromatography methods. Methanol and organic acids were quantified using a Porapak QS column with nitrogen as carrier gas and flame ionization detection. Samples were acidified with $\mathrm{HCl}$ and an internal standard (butan-2-ol) was added immediately before analysis. The gas phase within sealed tubes was analysed as described by Pacaud et al. (1985), but a $\mathrm{CO}_{2}$ probe (Ingold) was used to measure dissolved $\mathrm{CO}_{2}$ concentrations during fed-batch experiments.

Fermentation balances. Substrate:product balances were assessed at the end of each fermentation for the recovery of major elements (carbon, hydrogen and oxygen) and reducing equivalents.

Enzyme assays. Cell-free extracts were prepared from washed cells taken from late-exponential phase growth and broken by ultrasonic disintegration $(6 \times 30 \mathrm{~s})$. Cell debris was removed by centrifugation $(20 \mathrm{~min}$ at $20000 \mathrm{~g}$ and $4{ }^{\circ} \mathrm{C}$ ). The resulting lysate was used to measure the activity of acetate kinase (EC 2.7.2.1) and butyrate kinase (EC 2.7.2.7) in the following assay mixture: Tris/HCl buffer (100 mM, pH 7.6), ATP (4.2 mM), phosphoenolpyruvate (1.7 mM), $\mathrm{NADH}_{2}(0.4 \mathrm{~mm})$, pyruvate kinase (1 unit), lactate dehydrogenase (1 unit) and the potassium salt of one of several organic acids $(750 \mathrm{~mm})$. The activity was measured spectrophotometrically at $340 \mathrm{~nm}$ and $30^{\circ} \mathrm{C}$ and expressed as $\mu \mathrm{mol}$ substrate consumed $\min ^{-1}$ (mg protein) $)^{-1}$. Protein was quantified by the Lowry method using bovine plasma albumin as the standard protein

\section{RESULTS}

Growth rate inhibition. The observed inhibitory effects of organic acids on the methylotrophic growth of $E$. limosum confirmed the findings of Pacaud et al. $(1986 \mathrm{~b})$. All the organic acids tested had a similar effect on growth, characterized by a threshold concentration below which growth rates were unaffected $\left(\mu=0 \cdot 1 \mathrm{~h}^{-1}\right)$ but above which progressive inhibition took place. The threshold concentration was lower and the inhibitory effect more pronounced for organic acids of higher molecular mass.

Effect of butyrate on methylotrophic acidogenesis. Supplementation of the growth medium with butyrate brought about a progressive modification of metabolism as regards both substrate consumption and organic acid production (Fig. 1). At relatively low concentrations of butyrate 


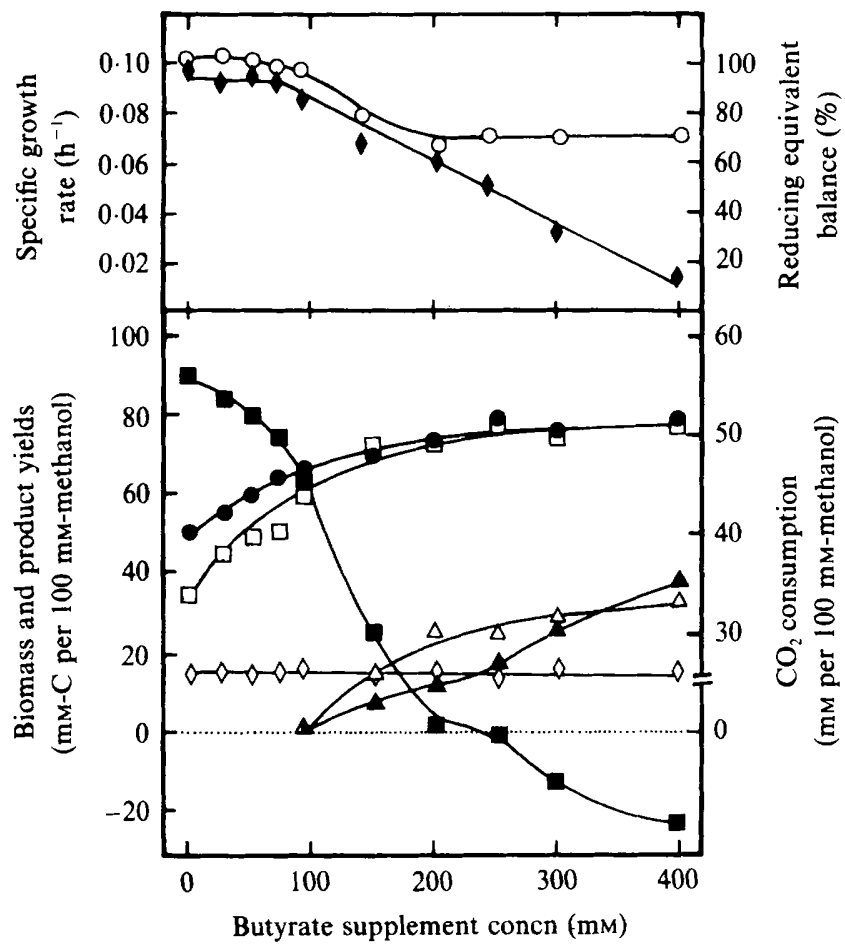

Fig. 1. Effect of butyrate supplements on organic acid production and substrate consumption during acidogenic fermentation of methanol/ $\mathrm{CO}_{2}$ by $E$. limosum. No residual methanol remained at stationary growth phase in any experiment. Negative values of organic acid production represent consumption of the supplement. $\square$, Acetate; $\square$, butyrate; $\Delta$, caproate; $\triangle$, unknown compound (calculated from $C$ balances); $\diamond$, biomass; $\odot, \mathrm{CO}_{2}$ consumed; $\diamond$, specific growth rate; $O$, reducing equivalent balance.

$(<100 \mathrm{~mm})$ the production of organic acids underwent a shift towards acetic acid facilitated by an increased consumption of $\mathrm{CO}_{2}$, i.e. less conversion of methanol to carboxyl donor. With increasing butyrate concentrations in the medium, butyrate production by the organism was halted and at concentrations above $200 \mathrm{~mm}$ consumption occurred. Homoacetic fermentations were not observed, however, since synthesis of caproic acid was seen to take place at butyrate concentrations above $100 \mathrm{~mm}$. An examination of the carbon balances obtained showed that some substrate carbon could not be recovered within the products; this carbon deficit increased relative to butyrate concentration in a similar manner to caproic acid production. The nature of this compound remains obscure, but it is believed to be related to the production of a viscous polymer isolated recently from dense cell cultures of methylotrophically grown $E$. limosum containing high concentrations of butyrate (Loubière et al., 1986). The reducing equivalent balance calculated from stoichiometric fermentation equations based on substrate:product analyses indicated that in order to maintain balanced fermentations at high butyrate concentrations some reducing equivalents need to have been used in the formation of this unidentified polymer.

Effect of propionate on methylotrophic acidogenesis. Supplementing the medium with propionate, a compound not normally produced by $E$. limosum, did not significantly affect the global consumption of either methanol or $\mathrm{CO}_{2}$. However, the production of organic acids was profoundly influenced (Fig. 2). Acetic acid production increased slightly relative to propionate concentration, reaching a maximum at approximately $200 \mathrm{~mm}$-propionate. Butyric acid production fell progressively and was replaced by valeric acid production at levels proportionate to the amount of propionate consumed. The decrease in the reducing equivalent balance (Fig. 2) 


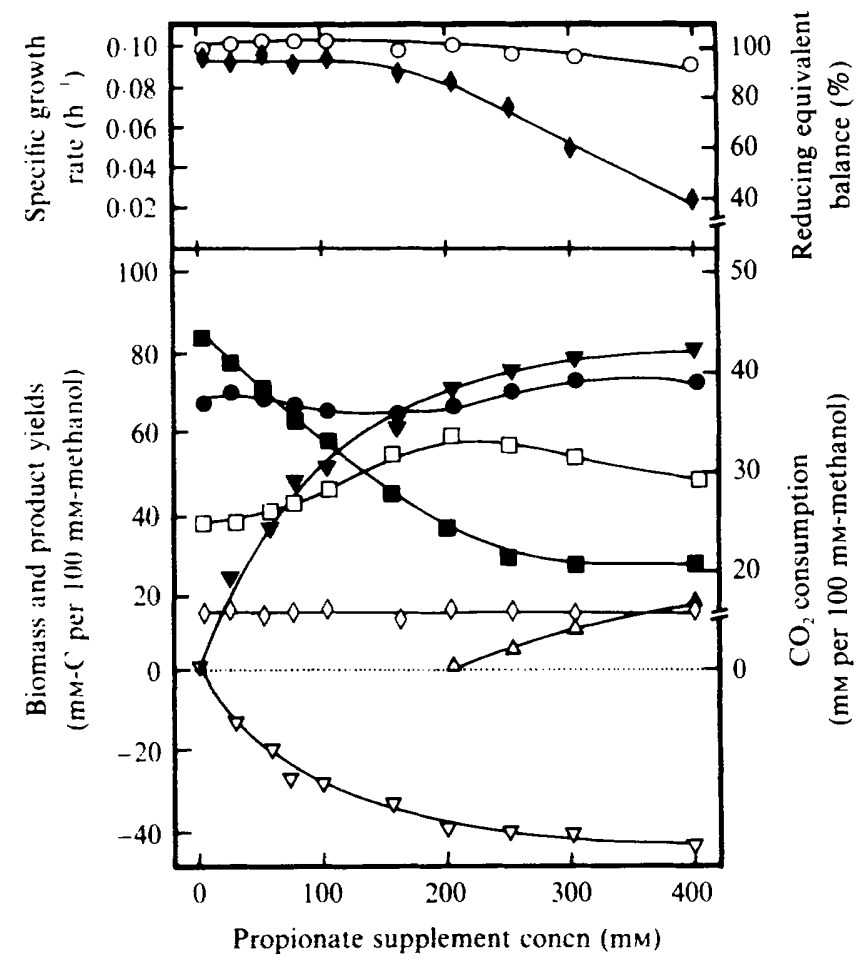

Fig. 2. Effect of propionate supplements on organic acid production and substrate consumption during acidogenic fermentation of methanol/ $\mathrm{CO}_{2}$ by $E$. limosum. No residual methanol remained at stationary growth phase. Negative values for organic acid production represent consumption of the supplement. $\square$, Acetate; $\square$, butyrate: $\nabla$. propionate; $\nabla$, valerate; $\diamond$, biomass; $\triangle$, unknown compound (calculated from $\mathrm{C}$ balances);, $\mathrm{CO}_{2}$ consumed; $\diamond$, specific growth rate; $\mathrm{O}$, reducing equivalent balance.

was again due to the use of some reducing equivalents for the formation of the unidentified compound, but the production of valerate rather than butyrate did not create major energy flow problems for E. limosum.

Effect of valerate and caproate on methylotrophic acidogenesis. In the presence of either valerate or caproate the ratio of methanol to $\mathrm{CO}_{2}$ consumed did not show any significant variation. At low concentrations of either supplement (i.e. $<50 \mathrm{~mm}$ ), production of the normally associated organic acids (butyrate and acetate) was not markedly affected. At supplement concentrations above $50 \mathrm{~mm}$, a major shift in production took place; production of butyric acid was greatly diminished and that of acetic acid enhanced. Both valerate and caproate were partially consumed, though to a lesser extent than propionate. Carbon balances showed that further products were synthesized in amounts suggestive of a $C_{2}$-unit elongation reaction, but this could not be confirmed due to limitations imposed by the available analytical facilities.

Substrate profile of acetate/butyrate kinase(s). The specific activity of acyl-kinase(s) was measured to determine whether or not the enzyme(s) normally present for conversion of acetyl$\mathrm{CoA}$ and butyryl-CoA, to acetate and butyrate, could be involved in the reverse reactions generating various acyl-CoA compounds from the respective organic acids. All assays were done with crude cell-free extracts from methanol-grown late-exponential-phase cells grown without organic acid supplements. No attempt was made to separate the various kinase activities, or to optimize the assay procedure for each substrate. The profile obtained (Table 1) resembled other results with anaerobic acidogens (e.g. Twarog \& Wolfe, 1962; Schaupp \& Ljungdahl, 1974; 


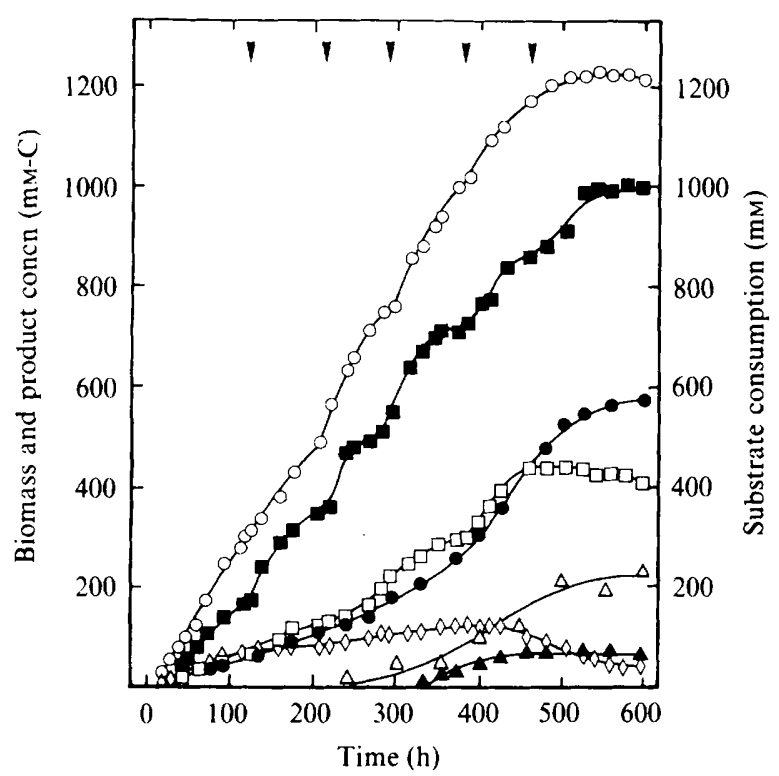

Fig. 3. Time course for a fed-batch fermentation of methanol/CO $\mathrm{CO}_{2}$ by . limosum at $37^{\circ} \mathrm{C}$ and $\mathrm{pH} 7.4$. Substrates and mineral requirements were added when necessary throughout the fermentation (arrowheads). $\bigcirc$, Methanol;, $\mathrm{CO}_{2} ; \square$, acetate; $\square$, butyrate; $\diamond$, biomass; $\Delta$, caproate; $\triangle$, unknown product (calculated from $\mathrm{C}$ balances).

Table 1. Specific activity and relative velocity of acetate/butyrate kinase(s) for various organic acids, in crude cell-free extracts of methanol-grown E. limosum

The assay procedure is described in Methods. Mean values of four independent determinations are shown; the variation between determinations was never greater than $10 \%$.

$\begin{array}{lcc}\begin{array}{c}\text { Assay } \\ \text { substrate }\end{array} & \begin{array}{c}\text { Specific activity } \\ {\left[\mu \mathrm{mol} \mathrm{min}^{-1}(\mathrm{mg} \text { protein })^{-1}\right]}\end{array} & \begin{array}{c}\text { Relative } \\ \text { velocity }\end{array} \\ \text { Acetic acid } & 1.12 & 1.0 \\ \text { Propionic acid } & 1.37 & 1.22 \\ \text { Butyric acid } & 1.55 & 1.38 \\ \text { Valeric acid } & 0.83 & 0.74 \\ \text { Caproic acid } & 0.19 & 0.17\end{array}$

Ichikawa et al., 1985) in which separate acetate and butyrate kinases each with multi-substrate affinity have been described. In $E$. limosum the specific activities were low but this probably reflected the physiological state of the culture and the non-optimized assay conditions.

$F e d-b a t c h$ fermentation of $E$. limosum on methanol. Fed-batch fermentations of $E$. limosum on methanol $/ \mathrm{CO}_{2}$ were undertaken to determine whether butyric acid produced in situ would bring about the same biotransformation reaction as observed for artificially supplemented cultures. The major physiological difference one might expect is that with in situ butyric acid production the ATP-generating kinase reactions might be halted, but they would be unlikely to be reversed. A fed-batch fermentation technique was essential to achieve organic acid concentrations sufficiently high to induce $C_{2}$-unit elongation reactions because of the relatively toxic nature of the substrates $\left(K_{\text {is }}\right.$ methanol $=500 \mathrm{mM} ; K_{\text {is }} \mathrm{CO}_{2}=250 \mathrm{mM}$ ). The results obtained (Fig. 3) show that in situ production of organic acids did indeed induce the same biotransformation reactions as did supplementing the medium with butyrate. Moreover, the butyrate concentration at which caproate synthesis was induced in fed-batch cultures was in close agreement with the results obtained with supplemented media. One interesting observation was that organic acid production and substrate consumption continued whilst the biomass levels were falling. 


\section{DISCUSSION}

Although a possible role for CoA-transferase reactions cannot be definitely excluded, it is generally believed that the conversion of butyryl-CoA to butyric acid by acidogenic bacteria is due to the action of phosphate acyltransferase and butyrate kinase. Such reactions have multisubstrate affinities and are reversible if the intracellular end-product (organic acid) concentrations increase beyond certain values. The efflux of organic acids from the cell into the culture broth (or in the reverse direction, i.e. uptake) is thought to be by passive diffusion of the undissociated acid; the intracellular concentration will thus be dependent upon the protonmotive force and in particular the $\Delta \mathrm{pH}$, which will fix the relative percentages of free and dissociated acids on either side of the cell membrane. A positive $\Delta \mathrm{pH}$ has been demonstrated for acidogenic anaerobes, i.e. an intracellular $\mathrm{pH} 0.5-1.0$ units higher than the culture $\mathrm{pH}$ (Menzel \& Gottschalk, 1985), so organic acids might be expected to accumulate within the cell to concentrations approximately fivefold higher than in the culture broth. Significant production of caproic acid was not observed until the butyric acid concentration (either supplemented or produced in situ) reached approximately $150 \mathrm{~mm}$, which, allowing for the $\Delta \mathrm{pH}$, would mean that intracellular butyrate concentrations would have been in the order of $750 \mathrm{~mm}$. At such concentrations, the butyrate kinase activity, when assayed in vitro, was operative in the reverse direction, i.e. butyrate was phosphorylated with ATP. During acidogenesis, ATP is generally present in excess of requirements (Papoutsakis, 1984), therefore it is likely that an accumulation of butyryl-phosphate, and ultimately butyryl-CoA, would occur. High butyryl-CoA concentrations could well function as the trigger mechanism for the production of alternative fermentation end-products. Since this $\mathrm{C}_{2}$-unit extension was observed for non-typical organic acids, the reactions involved are evidently capable of operating with a range of substrates. The benefit to the organism is that a balanced metabolism can be maintained when the normally operating acidogenic pathways can no longer function.

In many natural environments the normal organic acid products of $E$. limosum would be rapidly consumed by other species, but methylotrophic strains of this bacterium were first isolated from the rumen (Genthner et al., 1981), where organic acids are often major fermentation end-products. Acidogenic metabolism demands that a balanced reducing equivalent status be maintained. In environments such as the rumen, the ability to couple reducing equivalent wastage to a biotransformation reaction involving the normal end-products of fermentation would be of survival value. Growth would continue, albeit at reduced rates, in conditions in which less versatile organisms could no longer maintain a balanced metabolism. It is surprising that more acidogenic species have not been shown to be capable of such $\mathrm{C}_{2}$-unit extension reactions. This characteristic is sufficiently rare in the literature to be used as a taxonomic criterion for the identification of Eubacterium species; only E. alactolyticum was believed to be capable of this biotransformation (Lewis \& Sutter, 1981).

There are several biotechnological implications of this biotransformation reaction. An upper limit for butyrate concentrations of approximately $20 \mathrm{~g} \mathrm{l}^{-1}$ will be imposed by the physiological characteristics of $E$. limosum. Moreover, at such levels the productivity will be decreased because of the growth-inhibitory effect of the butyrate. Coupling the fermentation to a liquidliquid, extraction-re-extraction device, such as that described recently by Nagai (1986), would enable cultures of $E$. limosum to be detoxified by continual removal of the end-products. This would ensure better rates of growth and therefore production, but more importantly, would also allow the organic acids to be concentrated as their salts into alkali to $25 \%(\mathrm{w} / \mathrm{v})$ solutions. The feasibility of coupling detoxification and the primary downstream processing step is currently being investigated in our laboratory. Biotechnological interest in the acidogenic fermentation of methanol is chiefly concerned with butyric acid production, but the possible potential of a more general $\mathrm{C}_{2}$-unit extension reaction deserves consideration; the yields of valeric acid from propionate may be worthy of further study, for example. Our research has been restricted to saturated short-chain organic acids: the economic value of the biotransformation would be much increased if the reaction could be shown to be operative for other compounds less easily manufactured by chemical synthesis. 
The importance of intracellular metabolite concentrations for the induction of secondary metabolic routes in the butyric acid bacteria has now been well established. Those organisms, such as Clostridium acetobutylicum, capable of the dehydrogenation reactions necessary to convert acidogenic products to solvents are regulated by a similar trigger mechanism (Soni et al., $1986)$ to that described here for $E$. limosum, the difference being the choice (or rather the available enzyme complement) of an alternative manner of re-cycling the excess reducing equivalents. It is possible that the product scope from methanol could be extended by a screening programme which imposed physiological stress upon the organism by blocking the primary routes of coenzyme re-cycling.

S. Pacaud and C. Mariotto were sponsored by CdF Chimie, France, and N. D. Lindley initially by a Royal Society Fellowship Award paid by SERC, UK, and later by CNRS, France.

\section{REFERENCES}

Genthner, B. R., Davis, C. L. \& Bryant, M. P. (1981). Features of rumen and sewage sludge strains of Eubacterium limosum, a methanol- and $\mathrm{H}_{2} / \mathrm{CO}_{2}$-utilizing species. Applied and Environmental Microbiology 42, 12-19.

ICHIKAWA, Y., MORI, N., MikI, S., HosoI, N. \& Kitamoto, Y. (1985). Purification and properties of acetate kinase from Propionibacterium freudenreichii. Journal of Fermentation Technology 63, 143-149.

Kerby, R., Niemczura, W. \& Zeikus, J. G. (1983). Single-carbon catabolism in acetogens: analysis of carbon flow in Acetobacterium woodii and Butyribacterium methylotrophicum by fermentation and ${ }^{13} \mathrm{C}$ nuclear magnetic resonance measurement. Journal of Bacteriology 155, 1208-1218.

LEWIS, R. P. \& SuTter, V. L. (1981). The Genus Eubacterium. In The Prokaryotes II, pp. 1903-1911. Edited by M. P. Starr, H. Stolp, H. G. Trüper, A. Balows \& H. G. Schlegel. Berlin: Springer-Verlag.

Loubière, P., Mariotto, C., Goma, G. \& Lindley, N. D. (1986). Application of the physiological characteristics of methylotrophic metabolism of Eubacterium limosum to improve the biotechnological production of butyric acid. In Biology of Anaerobic Bacteria, pp. 117-123. Edited by H. C. Doubourguier. Amsterdam: Elsevier.

Menzel, U. \& GotTschalK, G. (1985). The internal $\mathrm{pH}$ of Acetobacterium wieringae and Acetobacter aceti during growth and production of acetic acid. Archives of Microbiology 143, 47-51.

NAGAI, S. (1986). Anaerobic wastewater treatment with recovery of biogas and useful materials. In Proceedings of the Annual Meeting of Fermentation Technology, Osaka, pp. 100-107.

Pacaud, S., Loubière, P. \& Goma, G. (1985).
Methanol metabolism by Eubacterium limosum B2: effects of $\mathrm{pH}$ and carbon dioxide on growth and organic acid production. Current Microbiology 12 , 245-250.

Pacaud, S., Loubière, P., Goma, G. \& Lindley, N. D. (1986a). Organic acid production during methylotrophic growth of Eubacterium limosum B2, displacement towards increased butyric acid yields by supplementing with acetate. Applied Microbiology and Biotechnology 23, 330-335.

PaCAud, S., Loubière, P., Goma, G. \& Lindley, N. D. $(1986 b)$. Effects of various organic acid supplements on growth rates of Eubacterium limosum B2 on methanol. Applied Microbiology and Biotechnology 24, 75-78.

PAPOUTSAKIS, E. T. (1984). Equations and calculations for fermentations of butyric acid bacteria. Biotechnology and Bioengineering 26, 174-187.

SchaupP, A. \& LJUNGdahl, L. G. (1974). Purification and properties of acetate kinase from Clostridium thermoaceticum. Archives of Microbiology 100, 121129.

Soni, B. K., Soucaille, P. \& Goma, G. (1986). Effect of phosphate cycling on production of acetonebutanol by Clostridium acetobutylicum in chemostat culture. Biotechnology and Bioengineering Symposium 17, 239-252.

TWaroG, R. \& Wolfe, R. S. (1962). Enzymatic phosphorylation of butyrate. Journal of Biological Chemistry 237, 2474-2477.

ZeIXUS, J. G., LYND, L. H., ThOMPSON, T. E., KrzYcki, J. A., Weimer, P. G. \& HegGe, P. W. (1980). Isolation and characterization of a new methylotrophic acidogenic anaerobe, the Marburg strain. Current Microbiology 3, 381-386. 